\title{
SEROTAYPING AND SENSITIVITY TESTS OF PATHOGENIC ESCHERICHIA COLI ISOLATED FROM SALPINGITIS IN COMMERCIAL LAYING HENS.
}

\author{
HASSAN H.KH.; AML A.M. BAKHEET and NAGLAA M. ALI \\ Dept. of Poultry Diseases, Animal Health Research Institute, Assiut Egypt. \\ Email: hassankhali122@yahoo.com
}

\section{ABSTRACT}

Received at: 27/12/2014

Accepted: 7/2/2015
Reproductive system disorders of laying hens have been gaining increasing attention due to immense economic losses that are being inflicted by these conditions on the growing poultry industry. Salpingitis is considered as an important one of these disorders. In order to determine the incidence of salpingitis in laying hens, 1050 recently dead laying hens from commercial laying farm in Assiut province were necropsied. Among thesehens, $120(11.43 \%)$ cases showed lesions of salpingitis. Bacterial examination detected 103(85.8\%) bacterial cultures from 120 suspected cases of salpingitis that yielded Esherichia coli in 46 (38.3\%), Enterobacter spp in 31 (25.9\%), Klebsiella spp in $11(9.1 \%)$, Citrobacter spp in $8(6.7 \%)$ of these cases and mixed bacteria in $7(5.8 \%)$ cases. No bacteria were isolated from $17(14.2 \%)$ of the suspected cases and also from normal oviducts of healthy hens. The fourty-sixE. coli isolates were serotyped and examined for susceptibility to 13 antimicrobials. O-serogroup determination test showed that the isolates belonged to nine different $\mathrm{O}$ serogroups including: $\mathrm{O} 111$, O26, O125, O55, O114, O127, O86, O124 and O142 serogroups. The most prevalent serogroups were O111, O26, O125, O55 respectively. However the maximum antimicrobial resistance of the tested $E$. coli isolates was demonstrated to sulfamethoxazol $(100 \%)$, followed by amoxicillin $(97.8 \%)$, erythromycin and oxytetracycline $(89.1 \%$ for each), neomycin (87\%), ampicillin (80.4\%), kanamycin $(67.4 \%)$ and streptomycin $(60.9 \%)$, the minimal resistance was against gentamycin $(2.2 \%)$ then ciprofloxacin $(6.5 \%)$, norfloxacin $(10.9 \%)$, nalidixic acid and lincospectin (23.9\% for each). Multiple antimicrobial-resistant phenotypes (to 3 or more) were observed in $41 / 46(89.1 \%)$ of $E$. coli isolates and one isolate was resistant to all tested drugs. The obtained results were recorded and compared with other workers results.

Key words: Salpingitis E. coli Commercial layers Antibiotics sensitivity.

\section{INTRODUCTION}

Salpingitis is an inflammatory reaction of the oviduct (infundibulum, magnum and uterus region) which may contain liquid or caseous exudate, it is a common cause of death in layers, as poultry production intensified, however it's occurrence has also increased and may become the major cause of death and give the appearance of contagious disease. This condition tends to be found sporadically during necropsy of cull hens, when the bacteria spread into the body cavity through the compromised oviduct wall leads to concurrent peritonitis, which is termed salpingoperitonitis (Saif et al., 2003, McMullin, 2004 and Srinivasan et al., 2013). It is a complex condition associated with various infections including Mycoplasma and other bacteria especially $E$. coli. E. coli isolates are the most common bacteria which have been reported from many countries as a frequent cause of salpingitis in commercial layers (Fossum et al., 2009). Acute and chronic bacterial infection of the oviduct (salpingitis) are recorded in most commercial layers and may account for losses from $1 \%$ to $8 \%$ over a laying year with a mean incidence of about $4 \%$. The condition has variously called salpingitis, peritonitis and reproductive breakdown (Cumming, 2001). Out of 173 E. coli serogroups, the most commonly encountered in avian pathogenic E. coli (APEC) are O1, O2, O35, and O78 (Orskov and Orskov, 1992 and Barnes et al., 2003) although the order of prevalence varies in different countries and farms (Cortes et al., 2010). The presumptive diagnosis of E. coli salpingitis and peritonitis based on the clinical sings, macroscopic findings at post-mortem (Landman and Cornelissen, 2006).

Jones et al. (1978) represented that, reproductive disorders were the commonest cause of death in the 
broiler breeder females. Egg peritonitis was the most important of these $(61.2 \%)$ followed by salpingitis $(20.7 \%)$ and prolapse of the oviduct $(7.8 \%)$.

Monroy et al. (2005) isolated thirty isolates of $E$. coli from broiler breeders with salpingitis, the isolates were found belong to serogroups $\mathrm{O} 1, \mathrm{O} 2$, O5, O36, O45, O53 and $\mathrm{O} 78$.

Trampel et al. (2007) revealed that peritoneal cavity and oviducts of normal chickens without lesions of peritonitis did not contain $E$. coli, while $E$. coli was isolated from peritoneal cavity of $13 / 15$ and from oviducts in 15/15 cases of peritonitis. The data suggest that all chickens with peritonitis in a single flock were likely infected by the same $E$. coli strain. $E$. coli isolates from the magnum and peritoneum had the same serogroup, virulence genotype, and phylogenetic group.

Ozawa et al. (2008) reported that, antimicrobial resistance of $E$. coli isolates was found for ampicillin (77.1\%), oxytetracycline $(75.9 \%)$, kanamycin (36.1\%), fradiomycin (33.7\%), trimethoprim $(25.3 \%)$, enrofloxacin $(21.7 \%)$, and florfenicol (6.0\%). Although multiple antimicrobial-resistant phenotypes (three or more antimicrobials) accounted for $54.2 \%$ of isolates, no isolate exhibited resistance to all tested agents.

Ozakiand Murase, (2009) found that, analysis of 22 $E$. coli isolates obtained from liver, heart, and the surface of the reproductive tract of one bird were genetically unrelated with those recovered from the lumen of the oviduct. In the other birds, isolates from liver, heart, and reproductive tract lesions were closely related to each other. These findings suggest that salpingitis in the former bird may be caused by ascending infection of the oviduct from the cloacae and in the remaining birds may occur as part of systemic infection.

Salehi and Ghanbarpour, (2010) isolated E.coli from commercial layer hens with salpingitis. The O-serogroup determination test showed that 47 $(38.84 \%)$ isolates were typeable and belonged to eleven different $\mathrm{O}$ serogroups (O1, O2,O6, O8, O15, O20, O25, O36, O78, O86 and O111) while $71(58.67 \%)$ isolates were O-nontypeable. The most prevalent serogroups were $\mathrm{O} 78, \mathrm{O} 2$ and $\mathrm{O} 1$ respectively. The maximum antibiotic resistance was against tetracycline $(100 \%)$ and minimum resistance was against lincospectin (37.19\%). Twenty four isolates $(19.83 \%)$ were resistant to all of the examined antibiotics and twenty three isolates showed different patterns of multiple drug resistance. They concluded that, there are similarities between $E$. coli isolates causes salpingitis and other avian pathogenic E. coli isolates in O-serogroups and antibio-resistance patterns.
El-Gohary et al. (2012) investigated three commercial poultry farms with different types of production; breeders, layers and broilers besides three hatcheries for the occurrence of Salmonella and $E$. coli organisms as index of biosecurity status. The results revealed that all E. coli strains were $100 \%$ sensitive to amikacin, nitrofurantion, chloramphenicol, polymyxin $\mathrm{B}$, ceftriaxone and enrofloxacin. On the other hand, all of tested strains exhibited absolute (100\%) resistance against streptomycin, neomycin and nalidixic acid.

Srinivasan et al. (2013) showed that, E.coli associated egg peritonitis was responsible for $15.39 \%$ of the reproductive system abnormalities in commercial layers. E. coli was isolated as pure culture and concurrent with other bacterial agents in 226 and 38 birds respectively. Among the fifteen $E$. coli serotypes identified serotype 0166, O64 and O111 were predominant.

Srinivasan et al. (2014) indicated that the oviduct impaction was responsible for $0.87 \%$ of the reproductive tract abnormalities in commercial layers. Among the 45 birds with impacted oviduct lesions, E. coli was isolated as a pure culture in 29, whereas in the remaining 16 birds was isolated along E. coli with other bacteria Proteous spp., Klebsiella spp. and Streptococcus spp. Serotyping of E. coli isolates revealed 7serogroups (O144, O54, O109, O3, O12, O88, and O118).

The aim of this study was to determine the E. coli serovars (serogroups) and antibiotics resistance of E. coli isolated from salpingitis cases in commercial layers in Assiut province (Egypt).

\section{MATERIALS and METHODS}

I - Case history: Recently dead laying hens were collected from farm of commercial cage layers in Assuit Province (Egypt). The flocks were Lohman type with age ranged from $25-68$ weeks. The flocks were vaccinated against Avian influenza, Marek's disease, Newcastle disease, Infectiousbursal disease, Infectious bronchitis, Infectious coryza, Fowl poxand Egg drop syndrome. The birds were received ration containtetracycllin and lincomix as feed additives.

II - Samples: A total number of 1050 recently deadhens were subjected to post- morteum examination. From these birds, oviducts of 120 hens showed various types of abnormalities (in it's color or consistency) identified as salpingitis or salpinoperitonitis were collected. The oviducts were removed and opened along it's longitudinal axis for examination of internal contains. Also 20 normal oviducts were obtained from clinically healthy laying hens after slaughtering. Swabs were 
collected from oviducts to bacteriological examination.

III - Isolation and identification of the $E$. coli isolates: Swabs of oviducts were collected (from dead birds with salpingitis lesions and that from clinically healthy laying hens) for screening of $E$. coli bacterial agents. The samples were placed in brain heart infusion broth and incubated at $37{ }^{\circ} \mathrm{C}$ for $24 \mathrm{~h}$ and cultured aerobically on MacConkey agar and eosin methylene blue agar (EMBA) for isolation of bacteriaas described by Olsen et al. (2011). Bacterial isolates were identified on the basis of their morphology, growth characteristics, sugar fermentation and biochemical characteristics according to Quinn et al. (2011). Strains of E. coli were stored at $-20{ }^{\circ}$ Cinbrain heart infusion (BHIDifco) broth containing $15 \%$ glycerol according to Monroy et al. (2005).

IV- Serological identification of $E$. coli: pure cultures of each isolate were serotyped using standard references $E$. coli antisera (DENKA SEIKEN Co., Japan). They include 8 vials of polyvalent in addition to the 44 vials of monovalent antisera and $7 \mathrm{H}$-sera. The isolates were serologically identified according to Kok et al. (1996) by using rapid diagnostic E. coli antisera sets (DENKA SEIKEN Co., Japan) for diagnosis of the Enteropathogenic types.

V- Antibiogramme for $E$. coli isolated from salpingitis in commercial laying hens: In-vitro antimicrobial susceptibility determination was tested by the single-disc diffusion method according to Mary and Usha (2013). Sensitivity discs with variable concentrations were used to determine the susceptibility of the isolated E.coli strains (Oxoid Limited, Basingstoke, Hampshire, UK). Muller-Hinton agar (Oxoid, Basingstoke, UK) was prepared in a uniform thickness (4 mm) for testing of $E$. coli isolates. The $E$. coli strains were tested against 13 antimicrobial agents that represent the commonly used antimicrobials in veterinary therapy. The tested antimicrobials

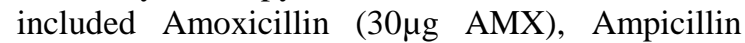
$(10 \mu \mathrm{g}$ AM), Ciprofloxacin $(5 \mu \mathrm{g}$ CP), Erythromycin

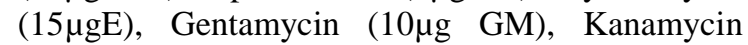

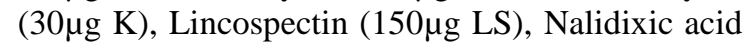

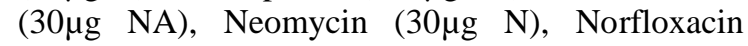

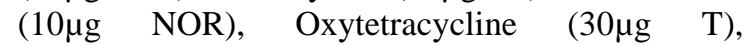

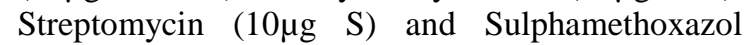

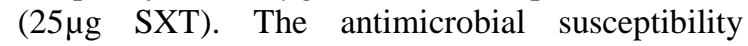
testing was applied and interpretated according to the guidelines stipulated by National Committee for Clinical Laboratory Standards "NCCLS" (2001).

\section{RESULTS}

Out of 1050 recently dead hens from commercial laying farm were subjected to postmortem examination to detect birds that show various types of oviduct abnormalities, $120(11.43 \%)$ were identified as salpingitis or salinoperitonitis. They were examined bacteriologically to detect incidence of bacterial species associated salpingitis especially E. coli (Tables,1), E. coli serovars (Table,2), percentages of antimicrobial susceptibility of E.coli spp (Table,3) and antimicrobial resistance profiles of E.coli isolates (Table,4). The bacteriological examination did not detect bacterial isolates from normal oviducts of clinically healthy birds.

Table 1: Bacterial species and strains isolated from salpingitis in commercial layers $(n=120)$

\begin{tabular}{|c|c|c|c|c|c|}
\hline Bacterial spp & Identified strains & $\begin{array}{l}\text { No of } \\
\text { isolated } \\
\text { strains }\end{array}$ & $\begin{array}{c}\% \text { of } \\
\text { isolated } \\
\text { strains }\end{array}$ & $\begin{array}{l}\text { Total No. of } \\
\text { isolates } \\
\text { in each } \\
\text { bacterial spp }\end{array}$ & $\begin{array}{c}\% \text { of } \\
\text { each } \\
\text { bacterial } \\
\text { spp }\end{array}$ \\
\hline E. coli spp. & E. coli & 46 & 38.3 & 46 & 38.3 \\
\hline \multirow[t]{4}{*}{ Enterobacter spp } & Enterobacter aerogenes & 15 & 12.5 & 31 & 25.9 \\
\hline & Enterobacter cloacae & 11 & 9.2 & & \\
\hline & Enterobacter agglomerans & 4 & 3.3 & & \\
\hline & Enterobacter hafniae & 1 & 0.9 & & \\
\hline \multirow[t]{2}{*}{ Citrobacter spp } & Citrobacter freundii & 7 & 5.8 & 8 & 6.7 \\
\hline & Citroubacter diverss & 1 & 0.9 & & \\
\hline \multirow[t]{2}{*}{ Klebsiella spp. } & Klebsiella pneumoniae & 7 & 5.8 & 11 & 9.1 \\
\hline & Klebsiella ozaenae & 4 & 3.3 & & \\
\hline Mixed bacteria & Mixed bacteria & 7 & 5.8 & 7 & 5.8 \\
\hline Total & & & & 103 & 85.8 \\
\hline
\end{tabular}


Table 2: $E$. coli serogroups isolated from salpingitis in commercial layers ( $n$ of $E$. coli=46).

\begin{tabular}{llcc}
\hline \multicolumn{1}{c}{ O-group } & Strain characterization & Number of strains & $\%$ \\
\hline O111 : H4 & EHEC & 13 & 28.3 \\
\hline O26 : H11 & EHEC & 7 & 15.2 \\
\hline O125: H21 & ETEC & 7 & 15.2 \\
\hline O55 : H7 & EPEC & 6 & 13.0 \\
\hline O114: H21 & EPEC & 5 & 10.9 \\
\hline O127 : H6 & ETEC & 3 & 6.5 \\
\hline O86 & EPEC & 2 & 4.4 \\
\hline O124 & EIEC & 2 & 4.4 \\
\hline O142 & EAEC & 1 & 2.1 \\
\hline Total & & 46 & 100 \\
\hline
\end{tabular}

Table 3: Percentages of antimicrobial susceptibility of E.coli spp. $(n=46)$.

\begin{tabular}{lllll}
\hline \multirow{2}{*}{ Antimicrobial agent } & \multicolumn{2}{c}{$S$} & & $R$ \\
\cline { 2 - 5 } & $\mathrm{NO}$ & $\%$ & $\mathrm{NO}$ & $\%$ \\
\hline Sulphamethoxazol (SXT) & 0 & 0 & 46 & 100 \\
\hline Amoxicillin (AMX) & 1 & 2.2 & 45 & 87.8 \\
\hline Erythromycin (E) & 5 & 10.9 & 41 & 89.1 \\
\hline Oxytetracycline (T) & 5 & 10.9 & 40 & 87.0 \\
\hline Neomycin (N) & 6 & 13.0 & 37 & 80.4 \\
\hline Ampicillin (AM) & 9 & 19.6 & 31 & 67.4 \\
\hline Kanamycin (K) & 15 & 32.6 & 28 & 60.9 \\
\hline Streptomycin (S) & 18 & 39.1 & 11 & 23.9 \\
\hline Linco-spectin (LS) & 35 & 76.1 & 11 & 23.9 \\
\hline Nalidixic acid (NA) & 35 & 76.1 & 5 & 10.9 \\
\hline Norfloxacin (NOR) & 41 & 89.1 & 3 & 6.5 \\
\hline Ciprofloxacin (CP) & 43 & 93.5 & 1 & 2.2 \\
\hline Gentamycin (G) & 45 & 97.8 & & \\
\hline
\end{tabular}

Table 4: Antimicrobial resistance profiles of E.coli isolated from salpingitis in commercial layers. $(n=46)$.

\begin{tabular}{clc}
\hline NO & \multicolumn{1}{c}{ Antimicrobial resistance profile } & Total $(n=46)$ \\
\hline 1 & SXT, AMX, E, T, N, AM, K, S, LS, NA,NOR, CP, G & 1 \\
\hline 2 & SXT, AMX, E, T, N, AM, K, S, LS,NA, NOR, CP & 2 \\
\hline 3 & SXT, AMX, E, T, N, AM, K, S, LS,NA, NOR & 2 \\
\hline 4 & SXT,AMX, E, T, N, AM, K, S, LS,NA & 2 \\
\hline 5 & SXT, AMX, E, T, N, AM, K, S, LS, NA & 4 \\
\hline 6 & SXT, AMX, E, T, N, AM, K, S & 17 \\
\hline 7 & SXT, AMX, E, T, N, AM, K & 3 \\
\hline 8 & SXT, AMX, E, T, N, AM & 3 \\
\hline 9 & SXT, AMX, E, T, N & 1 \\
\hline 10 & SXT, AMX, E, T & 4 \\
\hline 11 & SXT, AMX & 1 \\
\hline 12 & SXT
\end{tabular}




\section{DISCUSSION}

Enterobacteriaceae form a large heterogeneous family of medically and scientifically important gramnegativebacteria. E. coli, the most prevalent infecting organism in this family, is one of the prototypic bacteria studied (Carnes and Wilkins, 2005). Coliform salpingitis/ salpingoperitonitis results indecreased egg production and sporadic mortality. It isone of the most common causes of mortality in commercial layers and breeder chickens (Saif et al., 2003).

The results of the present investigation indicated that the E. coli and other bacteria can not isolated from normal oviducts of healthy layers. Trampel et al. (2007) recorded that, oviducts of normal chickens did not contain $E$. col. The location of $E$. coli in chickens producing eggs confirms that this bacterium is associated with disease and is not part of the normal micro flora found in the oviduct or peritoneal cavity. Healthy laying hens had E. coli within the cloacae but not in the oviduct or peritoneal cavity.

In this study, Enterobacterecaea associated salpingitis were responsible for (120/1050)11.43\% of the reproductive tract abnormalities in commercial layers between 25 and 68 weeks of age. Also results of Bandyopadyay and Dhawedkar (1984) recorded $11.25 \%$ of salpingioperiton it is in layers. Nili and Mahjour, (2005) determined $(8.26 \%)$ as the incidence of salpingitis, oophoritis and egg peritonitis in cull laying hens from commercial laying farms. Jones et al. (1978) mentioned that, the bacterial organisms (predominantly coliform) associated with cases of peritonitis and salpingitis and were interpreted as ascending infections. They diagnosed salpingitis in $24 / 116(20.7 \%)$ of female reproductive disorders in broiler breeders.

In the present study bacterial cultures of 120 suspected cases of salpingitis revealed 103 bacteria isolates with incidence of $85.8 \%$ (Table, 1). This nearly agree with results of Nili and Mahjour (2005) who detected 79 bacterial isolates from 86 suspected cases of inflammatory reactions of the ovary, the oviduct and the peritoneal cavity with incidence of $(91.86 \%)$.

The bacterial isolates in this study included E. colispp in $46(38.3 \%)$ cases, Enterobacter spp in $31(25.9 \%)$ cases $\{15(12.5 \%)$ Enterobacteraerogenes, 11(9.2\%) Enterobacter cloacae, 4(3.3\%) Enterobacter agglomerans and 1(0.9\%) Enterobacter hafniae\}, Citrobacter spp in $8(6.7 \%)$ cases $\{7(5.8 \%)$ Citrobacter freundii and 1(0.9\%) Citrobacter diverss $\}$, Klebsiella spp in 11(9.1\%) cases $\{7(5.8 \%)$ Klebsiella pneumoniae and 4(3.3\%) Klebsiella ozaenae and mixed bacteria in 7(5.8\%) cases (Table, $1)$. No bacteria were isolated from $17(14.17 \%)$ cases of suspected cases of salpingitis. Nili and Mahjour, (2005) examined bacterial culture of 86 suspected cases of inflammatory reactions of the ovary, the oviduct and the peritoneal cavity. The examination yielded E. coli in $62(72.09 \%)$ of cases, Salmonella spp in $4(4.65 \%)$ of cases, Proteus Vulgaris in 2 $(2.33 \%)$ of cases and Klebsiella spp in $1(1.16 \%)$ of cases and mixed bacterial infection in $9(10.47 \%)$ cases. No bacteria were isolated from $8(9.30 \%)$ of suspected case. Salpingitis is a complex condition of chickens associated with various bacterial agents including E. coli, Gallibacterium anatis, Staphylococcus spp., Mannheimia haemolytica, Streptococcus bovis and occasionally Salmonella spp (Jordan et al., 2005; Neubauer et al., 2009). E. coli and other bacterial organisms (Proteousspp, Klebsiella spp, Staphylococccus spp, and Streptococcus spp) were isolated from peritoneal cavity, oviduct and cloacal swabs in all the dead birds with egg peritonitis lesion (Srinivasan et al., 2013). The results of present study and others show that $E$. coli was the main associated cause to salpingitis in commercial layers. Srinivasan et al. (2013) indicated that the E. coli associated egg peritonitis was responsible for $15.39 \%$ of the reproductive tract abnormalities in commercial layers between 21 and 80 weeks of age, they attributed the higher percentage of incidence might be to poor management practices and occurrence of more virulent $E$. coli serotypes in the affected farms. The birds at peak of production are more susceptible due to stress imposed by the stage of lay. Fossum et al. (2009) mentioned that $E$. coli isolates are the most common bacteria which have been reported from many countries as a frequent cause of disease in commercial laying hens.

In the present study, 46 isolates of APEC belonged to 9 serogroups were detected. The serogroups include O111, O26, O125,O55, O114, O127, O86, O124 and O142 serogroups (Table,2). Salehi and Ghanbarpour, (2010) isolated 47 strains of E. coli from commercial layer hens with salpingitis. The isolates were typeable and belonged to 11 serogroupes (O1, O2,O6, O8, O15, O20, O25, O36, O78, O86 and O111). Also Monroy et al. (2005) have reported that E. coli isolates from broiler breeders with salpingitis belong to serogroups O1, O2, O5, O36, O45, O53 and O78. Srinivasan et al. (2013) identified fifteen E. coli serotypes (O166, O64, O111, O5, O6, O8, O20, O29, O75, O83, O89, O96, O104, O119 and rough) from peritonitis in commercial layer chickens, the three predominant serotypes were (O166, O64 and O111). Srinivasan et al. (2014) detected7 E. coli serogroups (O144, O54, O109, O3, O12, O88, and 0118) from impacted oviducts in commercial white leghorn layer chicken. In the present study O111 serotype was the most predominant serovars. It was detected in oviducts of commercial layers as one of the most predominant serovars in different studies (Trampel et al., 2007; Salehi and Ghanbarpour, 2010 and 
Srinivasan et al., 2013). The serogroup O86 was deteced in salpingitis cases in this study and in study of Salehi and Ghanbarpou (2010). Eidand Erfan (2013) found that, O114, O125, O55, O111 and O26 serogroups were the most prevalent in broiler flocks in Sharkia Governorate (Egypt), also these serogoups were found predominant in our study. The other detected serogroups not reported in previously available literatures. Variation occurs in $\mathrm{O}$ serogroups of $E$. coli isolates according to geographic region but inmost studies the common serotypes of APEC isolates have been O1, O2, O35, and O78 (Saif et al., 2003).

Presently, antimicrobial therapy is one of the primary control measures for reducing morbidity and mortality due to APEC associated avian colibacillosis (Dho-Moulin \& Fairbrother, 1999 and Altekruse et al., 2002). However, the maximum resistance of the tested $E$. coli isolates in this study was demonstrated to sulfamethoxazol $(100 \%)$, followed by amoxicillin $(97.8 \%)$, erythromycin and oxytetracycline $(89.1 \%$ for each), neomycin (87\%), ampicillin (80.4\%), kanamycin (67.4\%)and streptomycin(60.9\%), the minimal resistance was against gentamycin (2.2\%) then ciprofloxacin (6.5\%), norfloxacin (10.9\%), nalidixic acid and linco - spectin $(23.9 \%$ for each) as represented in (Table, 3). Antimicrobial resistance profiles of E.coli strains were shown in (Table, 4). In the present study twelve different patterns of multiple drug resistance were observed. The isolates showed multi-drug resistance (resistant to three kinds of antibiotics), and more than 3 were up to $89.1 \%$ (41/46) of the drug-resistant strains and isolates resistant to more than 8 antibiotics were up to $23.9 \%$ (11/46), of which one E. coli isolates resistant to all tested antibiotics. Acquired multi drug resistance to antimicrobial agents creates an extensive trouble in case of the management of intra and extra intestinal infections caused by $E$. coli, which are a major source of illness, death, and increased healthcare costs (Gupta et al., 2001). Salehi and Ghanbarpour, (2010) studied sensitivity of $E$. coli strains isolated from salpingitis of commercial layers for antibiotics, the result agree with our results in the high resistance to tetracycline $100 \%$, sulfamethxazol (97.52\%), neomycin $(96.69 \%)$ and agree with low resistance to linco-spectin $(37.19 \%)$ and gentamicin $(45.45 \%)$, but differ in results of enrofloxacin $(88.42 \%)$, also twenty three different patterns of multiple drug resistance were observed. Akond et al. (2009) reported that, 50 identified E. coli strains from poultry sources were subjected to 13 antimicrobial agents to check their susceptibility. The tested strains were found resistant to penicillin, ciprofloxacin, riphampicin, kanamycin, streptomycin, cefixine, erythromycin, ampicillin, tetracycline, chloramphenicol and neomycin. None of the strains showed resistance to norfloxacin and gentamicin. This result in agreement with our result in different antibiotics resistance except for ciprofloxacin. Commensal E. coli strains from poultry have similar patterns of resistance but at lower frequencies (Gyles, 2008). Recent study provides clear evidence that a sequential medication of a broiler flock, with different antimicrobial classes during short periods of time for prophylactic objectives, was accompanied by a dramatic increase in both antimicrobial resistance rates and phenotype diversity of E. coli strains (Da Costa et al., 2008). Development of resistant pathogenic E. coli strains pose considerable threat to public health as these strains after ingestion, are capable of transferring their resistance toother pathogens through episomal transfer of R-factor (Johnson et al., 2008).

\section{CONCLUSION}

E. coli isolates are the most common bacteria which have been reported from manycountries as a frequent cause of salpingitis in commercial laying hens. Variation occurs in O-serogroups of $E$. coli isolates according to geographic region. It is important to carry out bacteriological examination to the flocks in order to investigate the bacterial affections with estimation of changes in their sensitivity to the used antibiotics, at the same time, directed our care to find alternative means for control to avoid antibiotic resistant bacteria.

\section{REFERENCES}

Akond, M.A.; Alam, S.; Hassan, S.M.R. and Shirin, M. (2009): Antibiotic Resistance of E. coli Isolated from Poultry and Poultry Environment of Bangladesh. Internet Journal of Food Safety, 11: 19-23.

Altekruse, S.F.; Elvinger, F.; Lee, K.Y.; Tollefson, L.K.; Pierson, E.W.; Eifert, J. and Sriranganathan, N. (2002): Antimicrobial susceptibilities of Escherichia coli strains from a turkey operation. J. Am. Vet. Med. Assoc. 221, 411-416.

Bandyopadyay, P.K. and Dhawedkar, R.G. (1984): Escherichia coli salpingioperiton it is in poultry. Indian Vet. J., 60: 348-349.

Barnes, H.J.; Vaillancourt, J.P. and Gross, W.B. (2003): Colibacillosis. In: Saif, Y.M. (ed.). Diseases of Poultry. 11th ed. Iowa State Press, Ames, pp: 631-656.

Carnes, E. and Wilkins, E. (2005): The development of anew, rapid, amperometric immunosensor for the detection of low concentrations of bacteria part II: optimization of the system for Escherichia coli. Am. J. Applied Sci., 2(23): 607-613.

Cortes, P.; Blanc, V.; Mora, A.; Dahbi, G.; Blanco, J.E.; Blanco, M.; Lopez, C.; Andreu, A.; Navarro, F.; Alonso, M.P.; Bou, G.; Blanco, J. and Llagostera, M. (2010): Isolation and characterization of potentially pathogenic 
antimicrobial-resistant Escherichiacoli strains from chicken and pig farms in Spain. Appl. Environ. Microbiol., 76: 2799-2805.

Cumming, R.B. (2001): The aetiology and importance of salpingitis in laying hens. Proc. Aust. Poult. Sci., 14: 194-196.

Da Costa, P.M.; Bica, A.; Vaz-Pires, P. and Bernardo, F. (2008): Effects of antimicrobial treatment onselection of resistant Escherichia coli in broilerfecal flora. Microb. Drug. Resist., 14: 299-306.MID: 19025467.

Dho-Moulin, M. and Fairbrother, J.M. (1999): Avian pathogenic Escherichia coli (APEC). Vet. Res. 30: 299-316.

Eid, S.A. S. and Erfan, A.M. (2013): Characterization of E. coli associated with highmortalityinpoultry flocks. Assiut Vet. Med. J., 59 (139): 51-61.

El-Gohary, F.A.G.; El-Bably, M.A. and Mohamed, A.A. (2012): In-vitro antibiotic sensitivity of isolated strains of Salmonella and E. coli from poultry farms. 7th Int. Søeci. Conf., Mansoura: $28-30$.

Fossum, O.; Jansson, D.S.; Etterlin, P.E. and Vagsholm, I. (2009): Causes of mortality in laying hens in different housing systems in 2001 to 2004. Acta Vet. Scand., 15: 51-53.

Gupta, K.; Hooton, T.M. and Stamm, W.E. (2001): Increasing antimicrobial resistance and the management of uncomplicated communityacquired urinary tract infections. Ann. Int. Med. 135: 41-50.

Gyles, C. (2008): Veterinary medicine and public health. Can Vet J., 24: 1163-1164. MID: 19252708.

Johnson, T.J.; Wannemuehler, Y.; Johnson, S.J.; Stell, A.L. and Doetkott, C. (2008): Comparison of extra-intestinal pathogenic Escherichia coli strains from human and avian sources reveals a mixed subset representing potential zoonotic pathogens. Applied Environ. Microbiol., 74: 7043-7050.

Jones, H.G.R.; Randall, C.J. and Mills, C.P.J. (1978): A Surveyofmortalityin three adult broiler breeder flocks. Avian Pathology, 7: 619-628.

Jordan, F.T.; Williams, N.J.; Wattret, A. and Jones, T. (2005): Observations on salpingitis, peritonitis and salpingoperiton it is in a layer breeder flock. Vet. Rec., 157(19): 573-577.

Kok, T.; Worswich, D. and Gowans, E. (1996): Some serological techniques for microbial and viral infections. In Practical Medical Microbiology (Collee, J.; Fraser, A.; Marmion, B. and Simmons, A., eds.), $14^{\text {th }}$ ed., Edinburgh, Churchill Livingstone, UK.

Landman, W.J. and Cornelissen, R.A. (2006): Escherichia coli salpingitis and peritonitis in layer chickens: an overview. Tijdschr Diergeneeskd, 131 (22): 814-22.
Mary, C. and Usha, M. (2013): Incidences of multidrug resistance Escherichia coli isolates in Panipuri sold in Bangalore. Inter. Food Res. J., 20 (2): 1007-1009.

McMullin, P. (2004): A pocket guid to poultry health and disease, on The Poultry Site Quick Disease Guide.

Monroy, M.A.R.; Knobl, T.; Bottinob, J.A.; Ferreira, C.S.A. and Ferreira, A.J.P. (2005): Virulence characteristics of Escherichia coli isolates obtained from broiler breeders with salpingitis. Comparative Immunology, Microbiology \& Infectious Diseases, 28: 1-15.

NCCLS "National Committee for Clinical Laboratory Standards" (2001): Performance standards for antimicrobial susceptibility testing. Supplement M100-S11. Villanova, PA, USA.

Neubauer, C.; De Souza-Pilz, M.; Bojesen, A.M.; Bisgaard, M. and Hess, M. (2009): Tissue distribution of haemolytic Gallibacterium anatis in laying birds with reproductive disorders. Avian. Pathol., 38: 1-7.

Nili, H. and Mahjour, A.A. (2005): Histopathological and bacteriological studies on the cull laying hens' reproductive system. Iranian journal of veterinary research, university of shiraz,6 (3): 84-90.

Olsen, R.H.; Stockholm, N.M.; Permin, A.; Christensen, J.P.; Christensen, H. and Bisgaard, M. (2011): Multi-locus sequence typing and plasmid profile characterization of avian pathogenic Escherichia coli associated with increased mortality in free-range layerflocks. Avian Pathology, 40(5): 437- 444.

Orskov, F. and Orskov, I. (1992): Escherichia coli serotyping and disease in man and animals. Can. J. Microbiol., 38, 699-704.

Ozaki, H. and Murase, T. (2009): Multiple Routes of Entry for Escherichia coli Causing Colibacillosis in Commercial Layer Chickens. J. Vet. Med. Sci. 71(12): 1685-1689.

Ozawa, M.; Harada, K.; Kojima, A.; Asai, $T$. and Sameshima, T. (2008): Antimicrobial susceptibilities, serogroups, and molecular characterization of avian pathogenic Escherichia coli isolates in Japan. Avian Dis. 52(3): 392-397.

Quinn, P.J.; Markey, B.K.; Leonard, FC.; Fitzpatrick, E.S.; Fanning, S. and Hartigen, P.J. (2011): Veterinary microbiology and microbial disease. $2^{\text {nd }}$ ed. USA: John Wiley \& Sons: 263286.

Saif, Y.M.; Fadly, A.M.; Glisson, J.R.; McDougald, L.R. and Nolan, L.K. (2003): Diseases of Poultry. 11th Edn., Wiley-Blackwell, London, pp: 1260.

Salehi, M. and Ghanbarpour, R. (2010): Characterization of Escherichia coli Isolates from Commercial Layer Hens with Salpingitis. 
American Journal of Animal and Veterinary Sciences 5 (3): 208-214.

Srinivasan, P.; Balasubramaniam, G.A.; Gopala Krishna Murthy, T.R. and Balachandran, P. (2013): Bacteriological and pathological studies of egg peritonitis in commercial layer chicken in Namakkal area. Asian Pac. J. Trop. Biomed., 3(12): 988-994.

Srinivasan, P.; Balasubramaniam, G.A.; Gopala Krishna Murthy, T.R. and Balachandran, P.
(2014): Prevalence and pathology of oviduct impaction in commercial white leghorn layer chicken in Namakkal region of India, Veterinary World, 7(8): 553- 558.

Trampel, D.W.; Yvonne Wannemuehler, Y. and Nolan, L.K. (2007): Characterization of Escherichia coliisolates from peritonitis lesions in commercial laying hens. Avian Diseases, 51: 840-844.

\title{
اجراء التصنيف السيرولوجى وإختبارات الحساسية للميكروب القولوني الممرض المعزول من قناة المبيض الملتهبة في دجاجات البيض التجاري
}

\author{
حسن خليل حسن ، أمل أحمد محسود بخيت ، نجلاء محمود على
}

Email: hassankhalil22@yahoo.com

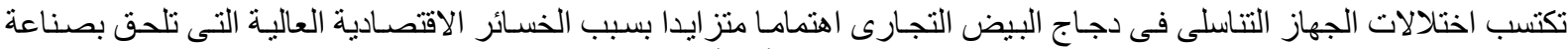

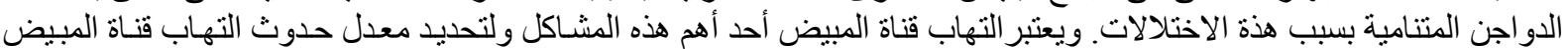

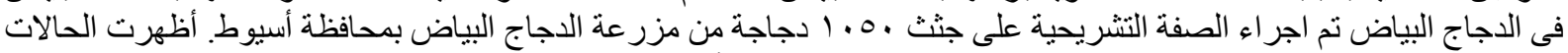

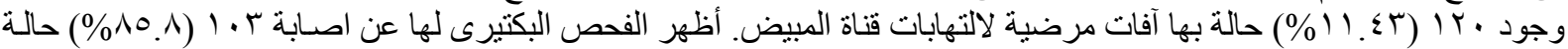

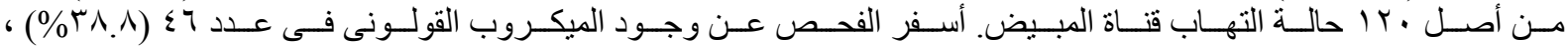

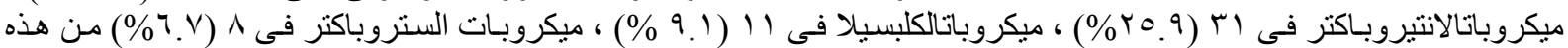

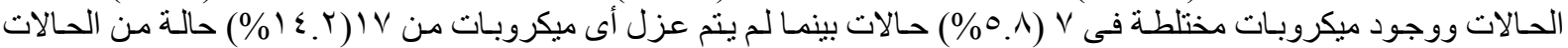

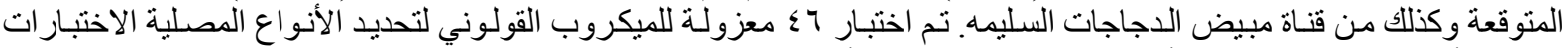

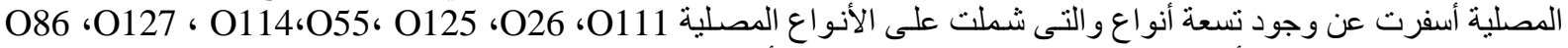

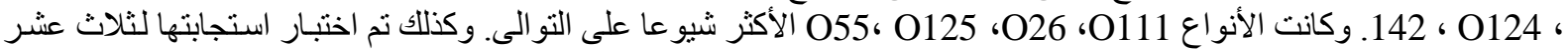

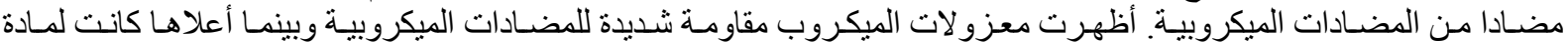

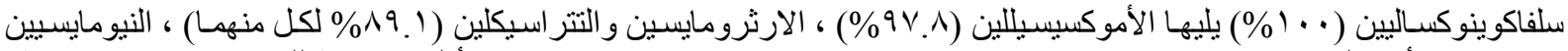

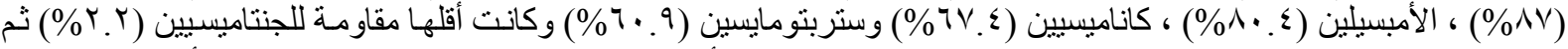

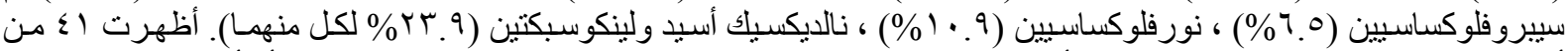

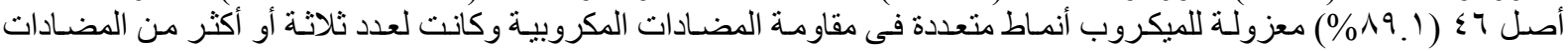

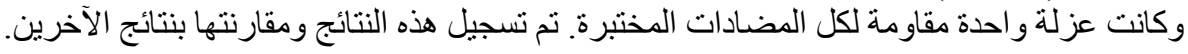

